\section{SERIAL SECTIONING} OF HARDENED CEMENT PASTE FOR SCANNING ELECTRON MICROSCOPY

\section{Paul E. Stutzman}

U.S. DEPARTMENT OF COMMERCE Natlonal Institute of Standards and Technology

Center for Bullding Technology Galthersburg, MD 20899
U.S. DEPARTMENT OF COMMERCE Robert A. Mosbacher, Secretary Loe Mercer, Deputy Under Secretary for Technology

NATIONAL INSTTUTE OF STANDARDS AND TECHNOLOGY

John W. Lyons, Director 



\section{Paul E. Stutzman}

U.S. DEPARTMENT OF COMMERCE Natlonal Institute of Standards and Technology

Center for Bullding Technology

Galthersburg, MD 20899

February 1890

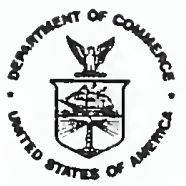

U.S. DEPARTMENT OF COMMERCE Robert A. Mosbacher, Secretary Lee Mercer, Deputy Under Secretary for Tochnology

NATIONAL INSTITUTE OF STANDARDS

AND TECHNOLOGY

John W. Lyons, Director 



\section{ABSTRACT}

Serial sectioning is a technique of making and examining thin sections of material to obtain information on three-dimensional structures from a series of two-dimensional images. Procedures were developed to make serial sections of hardened cement paste by the removal of thin layers by polishing. Backscattered electron imaging of the remaining paste block was used to record the paste microstructure after each section was removed.

Procedures developed cover the polishing practice, the removal of thin layers by polishing, the estimation of layer thickness, and the location and alignment of specific regions for imaging.

Key words: backscattered electron imaging; cement paste; Knoop indentation; microstructure; polishing; serial sectioning; scanning electron microscopy 

Page

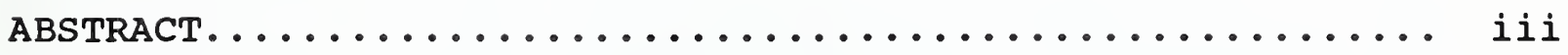

LIST OF FIGURES............................. vi

1. INTRODUCTION............................ 1

2. SECTIONING TECHNIQUES........................ 1

3. LABORATORY INVESTIGATION................... 2

3.1 Preparation of Hardened Cement Paste Sections.... 2

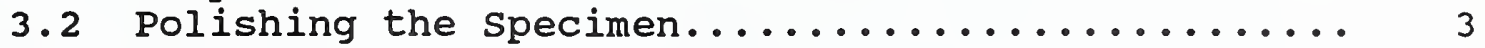

3.3 Estimation of Section Thickness.............. 4

3.4 SEM Imaging of Polished Sections............. 4

4. RESULTS AND DISCUSSION.................... 7

4.1 Specimen Preparation and Imaging............ 7

4.2 Images of Parallel Sections................ 8

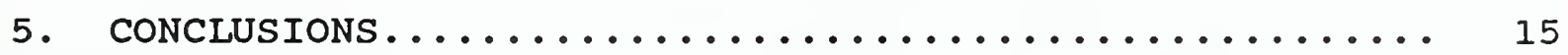

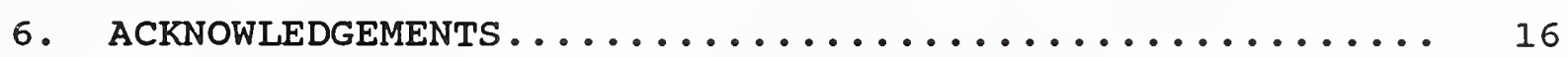

7. REFERENCES................................ 17 
Figure 1. (a) Backscattered electron image and line measurement of a knoop indentation in a polished paste section. (b) Profile of the

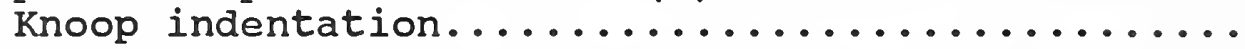

Figure 2. (a) Well-defined microstructure of a properlypolished section of epoxy-impregnated hardened cement paste with (A) clinker, (B) calcium hydroxide, (C) dense $\mathrm{C}-\mathrm{S}-\mathrm{H}$, and (D) porous $\mathrm{C}-\mathrm{S}-\mathrm{H}$. (b) Poorly-polished cement paste with rounded anhydrous cement grains and loss of

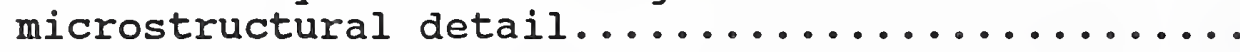

Figure 3. SEM micrographs of hardened $C_{3} S$ paste sections 1 (a) and 2 (b). (A) unhydrated $\mathrm{C}_{3} \mathrm{~S}$, (B) $\mathrm{C}-\mathrm{S}-\mathrm{H}$, (C) calcium hydroxide, and (P) pore........... 10

Figure 4. SEM micrographs of polished sections of hardened

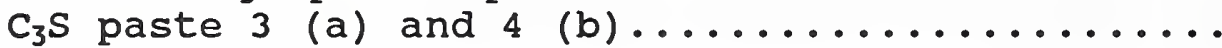

Figure 5. SEM micrographs of polished sections of hardened $\mathrm{C}_{3}$ S paste 5 (a) and $6(\mathrm{~b}) \ldots \ldots \ldots \ldots \ldots \ldots \ldots \ldots$

Figure 6. Serial polished sections of hardened portland cement paste. Partially hydrated cement grains
(A),
(B),
(C),
and pore system
(D) 
Scanning electron microscopy (SEM) with backscattered electron imaging (BEI) is an excellent tool for the examination of the microstructure of hardened cement paste [1,2]. The occurrence and interrelationships of the components of cement microstructure; unhydrated clinker, hydrated compounds, and porosity can be examined by SEM/BEI imaging of polished sections of epoxy-impregnated cement paste. Quantitative estimates of phase abundance in hardened cement paste can be made by computerbased analysis of these two-dimensional images.

In order to visualize the spatial relationships of the components (fabric) in cement paste, three-dimensional renditions of the paste microstructure need to be prepared and evaluated. Serial sectioning is a technique of preparing and imaging a series of thin sections in two dimensions to provide information on the third dimension of the microstructure. The objective of this study is to examine methods of removing thin (about one micrometer) sections of hardened cement paste, develop a technique to measure section thickness, refine the polishing procedure to eliminate specimen damage, and examine techniques for marking the specimen for alignment of adjacent images.

Reconstruction of a series of sections, if properly prepared and aligned, should result in a three-dimensional rendition of features of interest. This will help in estimating particle sizes, shapes, and distribution. For porosity and permeability studies, the pore system may be imaged and, depending on the lower limits of pore size detection, a three-dimensional reconstruction of the pore network can be made.

\section{SECTIONING TECHNIQUES}

Three methods of sectioning hardened cement paste were investigated; polishing, microtome, and ion beam thinning. The ideal method should produce thin sections of roughly equal thickness, be reproducible, and not damage the paste microstructure. Polishing is commonly used to prepare cement paste samples for imaging; microtome sectioning is a technique to obtain specimens for biological studies; and ion beam thinning is a common technique for the preparation of ultra-thin samples for transmission electron microscopy. 
The following is the sequence of steps involved with the preparation of cement paste samples for sectioning and imaging: (1) epoxy impregnation of the cement paste; (2) polishing and Knoop microhardness indentation; (3) SEM imaging to measure Knoop indentation and to record the microstructure; and (4) polishing to remove a thin layer of paste; (5) repeat steps 3 and 4 .

\subsection{Preparation of Hardened Cement Paste Sections}

A seven day old, 0.45 water-to-cement ratio tricalcium silicate $\left(\mathrm{C}_{3} \mathrm{~S}\right)$ paste was used in this study. $\mathrm{C}_{3} \mathrm{~S}$ was used for the initial experiments because the microstructure consists of only three crystalline phases, unhydrated $\mathrm{C}_{3} \mathrm{~S}$, calcium hydroxide, and calcium silicate hydrate $(\mathrm{C}-\mathrm{S}-\mathrm{H})$, as well as pores. Epoxyfilled pores are considered to be a phase for SEM imaging. The paste was molded in one centimeter cubes, allowed to set for one day, and cured in lime water (saturated $\mathrm{Ca}(\mathrm{OH})_{2}$ solution) for seven days. After curing, a cube was removed and wafered into fragments about three milimeters on a side for epoxy impregnation, potting, and polishing. Portland cement specimens used as trial samples were prepared the same way.

A procedure for epoxy impregnation of hardened paste samples can be found in struble and stutzman [3]. The impregnation procedure is a two step process where the pore solution is replaced by ethanol and then the ethanol is replaced by epoxy. Replacement of the pore solution by epoxy without drying the paste eliminates cracking caused by drying shrinkage. The cured epoxy provides most of the structural support to the cement paste. It also aids in backscattered electron imaging by filling the voids with a low average atomic number material, which appears darker than the crystalline phases when imaged by SEM/BEI.

Low and ultra-low viscosity epoxies ${ }^{1,2}$ miscible in ethanol are suitable for the replacement procedure and can be obtained from most electron microscopy materials suppliers.

A companion cube immersed in dyed ethanol was used to monitor the ethanol/pore solution replacement by sectioning after

${ }^{1}$ Certain commercial equipment, instruments, and materials are identified to specify adequately the experimental procedure. In no case does such identification imply recommendation or endorsement by the National Institute of standards and Technology, nor does it imply that the materials or equipment identified are necessarily the best available for the purpose.

${ }^{2}$ L.R. White resin, hard grade. 
a few days immersion and observing the dye front. This provided a direct view of the replacement rate and an estimate of the needed time for the ethanol/epoxy replacement step. For the seven day $C_{3} S$ samples, two to three millimeter cubic to rectangular specimens, two days in ethanol and four days in epoxy was adequate.

After ethanol/epoxy replacement the sample was potted using the same type of epoxy used in the replacement step. Curing required about 24 hours at $60^{\circ} \mathrm{C}$, a temperature high enough to cure the epoxy without dehydrating the cement paste [3]. Potted and cured specimens were removed from their molds and the back side was ground to remove the epoxy meniscus, taking care to keep the faces parallel. A diamond scribe was effective for etching the specimen label.

\subsection{Polishing the Specimen}

Rough grinding ( 240 and 400 grit) was used to remove the epoxy from the face of the specimen. All grinding was done dry, because grinding lubricants such as alcohol can soften the epoxy after prolonged contact and lift the epoxy from the voids. The paste surface appears frosted during rough grinding. As the epoxy is ground, exposing the paste surface, the paste appeared much smoother and highly reflective. With the paste exposed, the last grinding step with 600 grit sandpaper smoothed the surface in preparation for polishing. The final step of rough grinding was to clean the grit and powdered material from the specimen. The specimen was placed in a container filled with 200 proof ethanol and the container in an ultrasonic bath for about ten seconds. The specimen was rinsed with 200 proof ethanol from a plastic squirt bottle and dried with forced air.

The polishing procedure involves the repetition of a three step process (polish, clean, examination) with four grades of diamond polishing compound. Equipment and materials used were a lap wheel, low-nap wheel covering (Texmet), silk wheel covering, and diamond polishing compounds with particle sizes 6, 3, 1, and 0.25 micrometers ${ }^{3}$. The first polishing step used 6 micrometer diamond paste on silk cloth over Texmet. Finer grit diamond paste steps $(3,1$, and 0.25 micrometer) use only the Texmet. The specimens were polished using high pressure (about 15 pounds) while moving the sample in a direction opposite the wheel rotation for about fifteen seconds. Propylene glycol was sparingly used as a polishing lubricant, the diamond paste doing the cutting and polishing. The specimens were examined under a binocular microscope for evaluation of the polished surface. Scratches in the epoxy and sample from the diamond polish were

\footnotetext{
${ }^{3}$ Texmet, selected Silk, and Metadi II; Buehler, Lake Bluff, Illinois.
} 
readily apparent and become smaller as finer grades of polish were used. Coarse scratches, relative to the normal polishing scratches, indicate contamination or plucking of the sample. The

wheel cloth should be replaced to prevent repeated contamination if there is evidence of particle contamination.

\subsection{Estimation of Section Thickness}

Estimation of the thickness of cement paste removed was carried out by measuring the change in length of a Knoop indentation. The knoop Indenter is a diamond, rhombic in shape, with known tip dimensions. The knoop Indentation was applied to the polished sample surface by use of a microhardness tester ${ }^{4}$ with a 500 gram load to produce an indentation of about 0.2 to 0.5 millimeters in length. The profile of the knoop indentation can be viewed as two right triangles sharing a common side (fig. 1). The angles are known and the base (half the indentation length) can be measured using the line measuring capabilities of the SEM, or from a micrograph. The change in depth of the common side was calculated as indicated in figure 1. The change in depth was the thickness of the paste layer removed during the polishing step.

\subsection{SEM Imaging of Polished Sections}

The polished, indented samples were sputter-coated with a thin layer of gold to provide a conductive film. If $\mathrm{X}$-ray analysis was planned, carbon was evaporated on the specimen to avoid peak interference.

Samples were examined at $15 \mathrm{kV}$ accelerating voltage with a four-pole solid-state backscattered electron detector ${ }^{5}$.

Collection of the digital image for processing was by 256 point averaging of a 512 by 400 pixel grid. The image was saved as a computer file for further processing, creation of a binary image, or transfer to other image analysis systems.

After imaging, the samples were sectioned by repeating the final polishing step. The sample was polished with high pressure on the 0.25 micrometer polishing wheel for about 15 seconds, removing about one micron of material. The sample was cleaned for 10 to 15 seconds in 200 proof ethanol. After coating with a conductive material, the sample was ready for SEM examination.

\footnotetext{
${ }^{4}$ Tukon Hardness Tester, Wilson Mechanical Instrument Company, New York, New York.

${ }^{5}$ Cambridge Instruments $\$ 360$ scanning electron microscope with a Princeton Gamma Tech IMIX III X-ray microanalysis and image analyzer.
} 


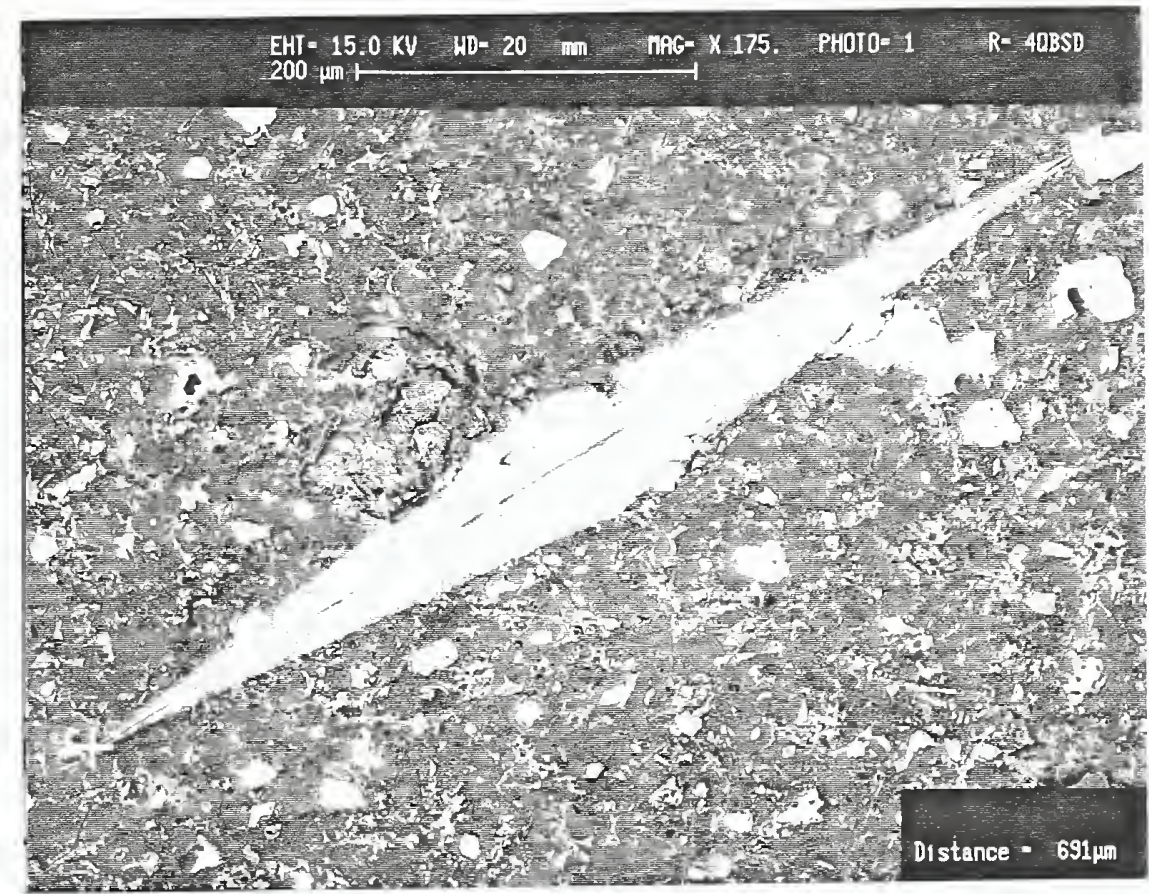

(a)

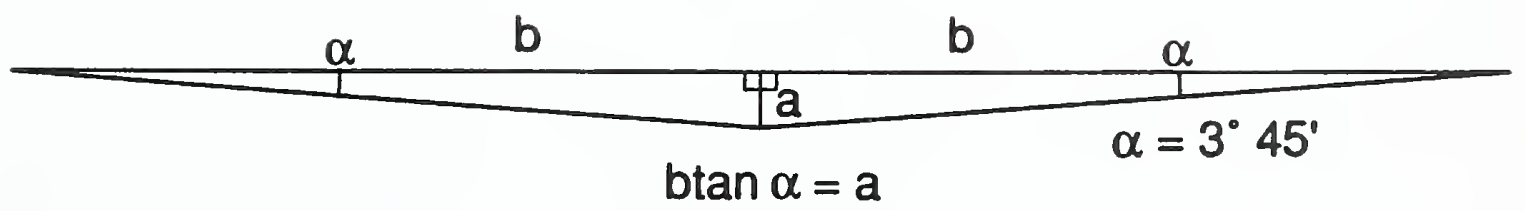

(b)

Figure 1. a) Backscattered electron image and line measurement of a knoop indentation in a polished cement paste section. b) Profile of the knoop indentation. 
Rotation and translation (left-right, up-down) was necessary for the accurate alignment of the sections and resulting images. Alignment of the sample in the SEM chamber using the stage controls was performed in two steps, coarse and fine adjustment. Coarse alignment involved rotating the sample to orient the Knoopindentation with the long axis parallel to either of the edges of the SEM viewing screen. The sample could be moved in the $\mathrm{x}$ and $\mathrm{y}$ direction to select a region of interest. Fine alignment could be made by visually matching the image with the micrograph from the previous section, orienting on common features such as an unhydrated grain or other distinct feature. selecting a region of interest for imaging close to the indentation aided in the location of the same region and in the orientation of the sample, especially if the microstructure changes drastically with depth. Experiments are underway where the electron beam is used to mark the sample in beam-sensitive regions such as calcium hydroxide or dense C-S-H. Use of three marks, if their depth exceeds the section thickness and are present after polishing, will facilitate image alignment. High current ( 3 nanoamps) was seen to open a crack in a dense $\mathrm{C}-\mathrm{S}-\mathrm{H}$ region of a portland cement specimen. This fissure, although not an original feature of the microstructure, was used successfully for alignment of three sections. 
4.1 Specimen Preparation and Imaging

Microtome sectioning, ion beam thinning, and polishing were evaluated to assess their suitability for making serial sections of hydrated cement paste.

Microtome sectioning is a method commonly used to make thin sections of epoxy-impregnated tissue for biological studies. The advantages of the microtome are that very thin sections can be quickly cut with a high degree of precision. Attempts to section the epoxy-impregnated paste were not successful. The tungsten carbide cutting blade of the microtome was chipped upon contact with the paste. The chipped blade tore at the paste, leaving striations in the direction of cutting damaging the microstructure. The blade damage was probably a result of the differences in hardness of the components of cement paste.

Ion beam thinning (milling) removes material by bombarding the sample with ionized argon molecules. $C_{3} S$ and portland cement paste samples were milled for 20 minutes using an argon beam operating at $5 \mathrm{kV}$ and $3 \mathrm{~mA}$. Ion beam thinning of $\mathrm{C}_{3} \mathrm{~S}$ samples was not satisfactory because of the relief resulting from the preferential eroding of the epoxy in the pores. This was not as evident in the portland cement paste samples, and could be a result of the finer microstructure of hardened portland cement paste. About two micrometers of material were removed from the cement paste sample. Pores and the hydrated phases were distinct and the boundaries between the phases were sharp. Some cracking of the cement paste specimens was observed which may have been a result of heat generated during the milling operation.

Polishing was selected as the method of sectioning for the following reasons: polishing is an effective method for removal of thin layers of material, the general techniques are used in most laboratories, the equipment is readily available, and it is low in cost and simple to operate. Sectioning by polishing has several advantages; (i) it does not damage the microstructure, (ii) it is capable of removing thin layers of cement paste, (iii) it is fairly rapid and reproducible, and (iv) it could be automated using pressure-controlled, multi-sample holders commercially available. Careful preparation, the avoidance of water and polishing grit contamination, will result in a specimen that can be sectioned many times with little or no damage to the microstructure.

Kinds of damage to the cement paste microstructure during the polishing stages are; (i) particle relief attributed to over polishing or the use of improper polishing materials, and (ii) etching of the cement paste due to the presence of water in the 
ethanol cleaning solution, the propylene glycol or humid storage conditions.

Backscattered electron imaging can be sensitive to topographical relief. Topographic relief due to the differing hardness of the components in the cement paste can produce a shadowing around high-relief particle edges. This shadowing is not representative of the true microstructure and appears as porosity. Sample relief can be minimized in the polishing stages by using a very-low-nap or no-nap polishing cloth, high pressure and short polishing times.

Water-etched paste is characterized by the loss of calcium hydroxide, loss of $\mathrm{C}-\mathrm{S}-\mathrm{H}$ and porosity microstructure detail. Etching can be minimized by using only 200 proof ethanol for cleaning and rinsing, by using only enough propylene glycol to moisten the lap wheel covering, and by storing the samples in a vacuum desiccator.

Figure 2 illustrates two examples of the extremes in polishing. Micrograph (a) illustrates the excellent microstructure definition, negligible water etching, and low polishing relief typical of a good polish. The epoxy-filled pores and differences between the dense and porous $\mathrm{C}-\mathrm{S}-\mathrm{H}$ are well defined. Calcium hydroxide is apparent as light gray masses. Micrograph (b) illustrates the almost complete loss of microstructural detail as a result of severe water etching. No distinction can be made between pores, porous $\mathrm{C}-\mathrm{S}-\mathrm{H}$ and dense $\mathrm{C}-$ S-H. Calcium hydroxide has been completely etched from the sample. The etched sample exhibits only rounded cement grains in an amorphous matrix. Some sample relief is also present with the resulting shadows in the low areas appearing as porosity.

Section thickness control is currently a trial and error procedure. The cured epoxy polishes at about the same rate as the cement paste and serves as a polishing moderator. Using 15 to 30 seconds polishing time on a 0.25 micrometer grit polishing wheel a reduction of block thickness of about one micrometer was obtained. Automated polishers with controllable pressure and polishing times probably would make this procedure more reproducible.

\subsection{Images of Parallel sections}

Figures 3 through 5 are a series of SEM micrographs of the microstructure of a seven-day-old $C_{3}$ S cement paste. Unhydrated $\mathrm{C}_{3} \mathrm{~S}$ appears brightest followed by the light gray calcium hydroxide, dark gray $\mathrm{C}-\mathrm{S}-\mathrm{H}$ and the black pore space. The spacing of these sections is about two micrometers. Alignment for these specimens was by eye, matching the field of view of the newly sectioned paste with the micrograph of the previous section. 


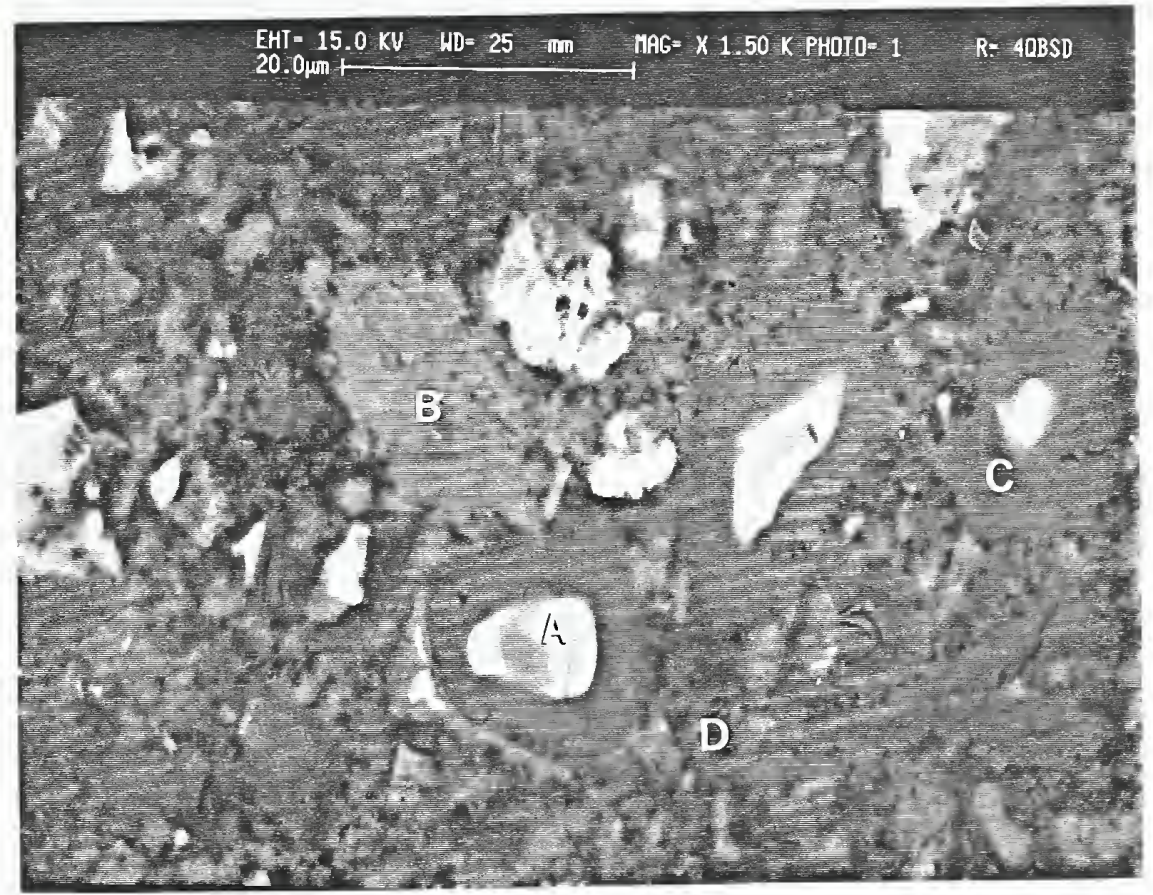

(a)

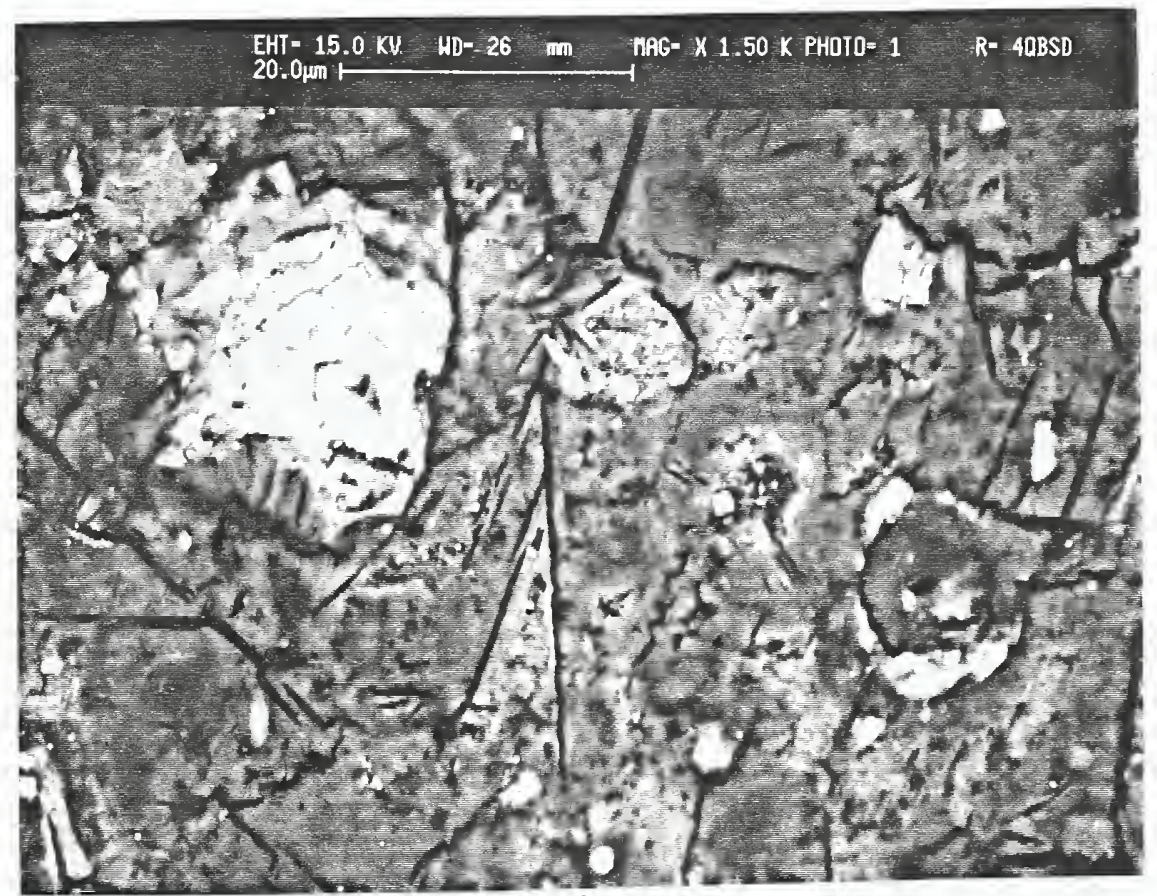

(b)

Figure 2. a) Well-defined microstructure of a properly-polished section of epoxy-impregnated hardened cement paste with (A) clinker, (B) calcium hydroxide, (C) dense C-S-H, and (D) porous $\mathrm{C}-\mathrm{S}-\mathrm{H}$. b) Poorly-polished cement paste with rounded anhydrous cement grains and loss of microstructural detail. 


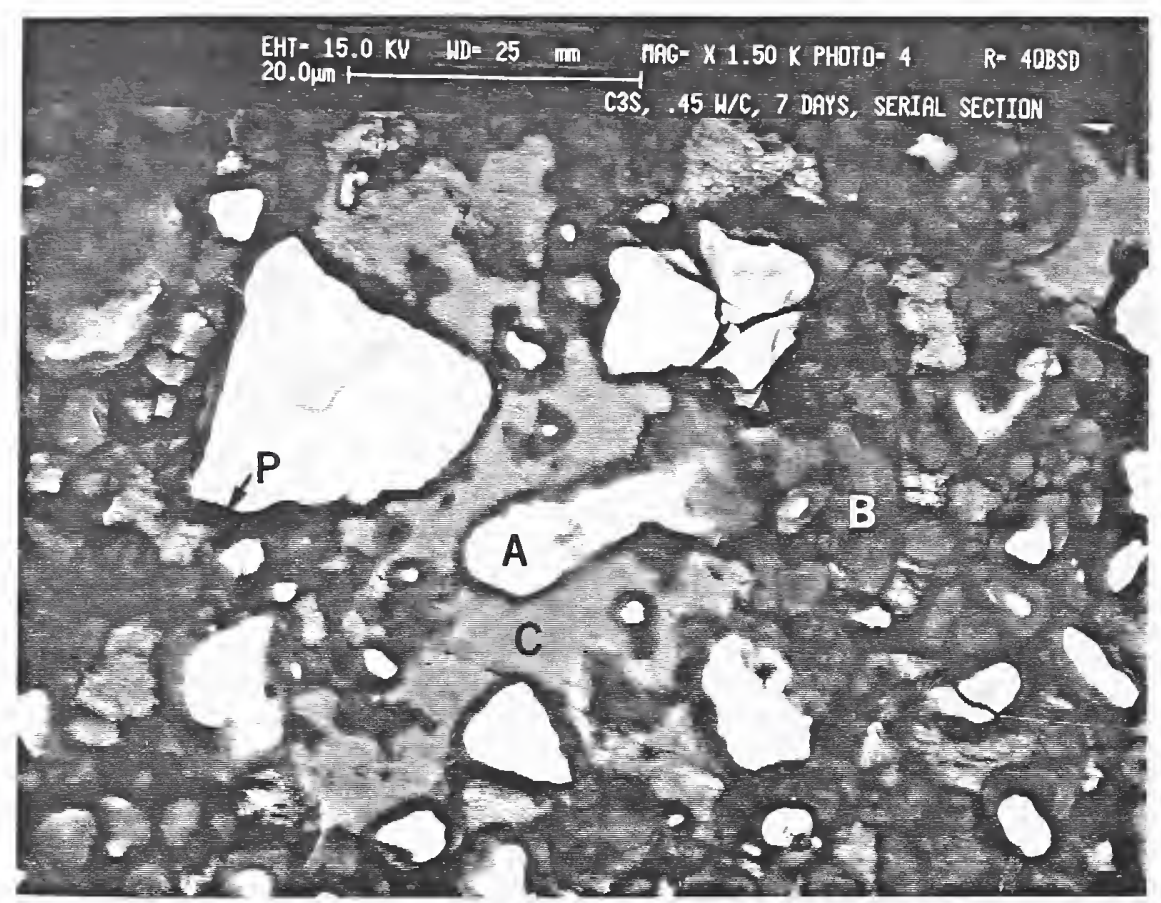

(a)

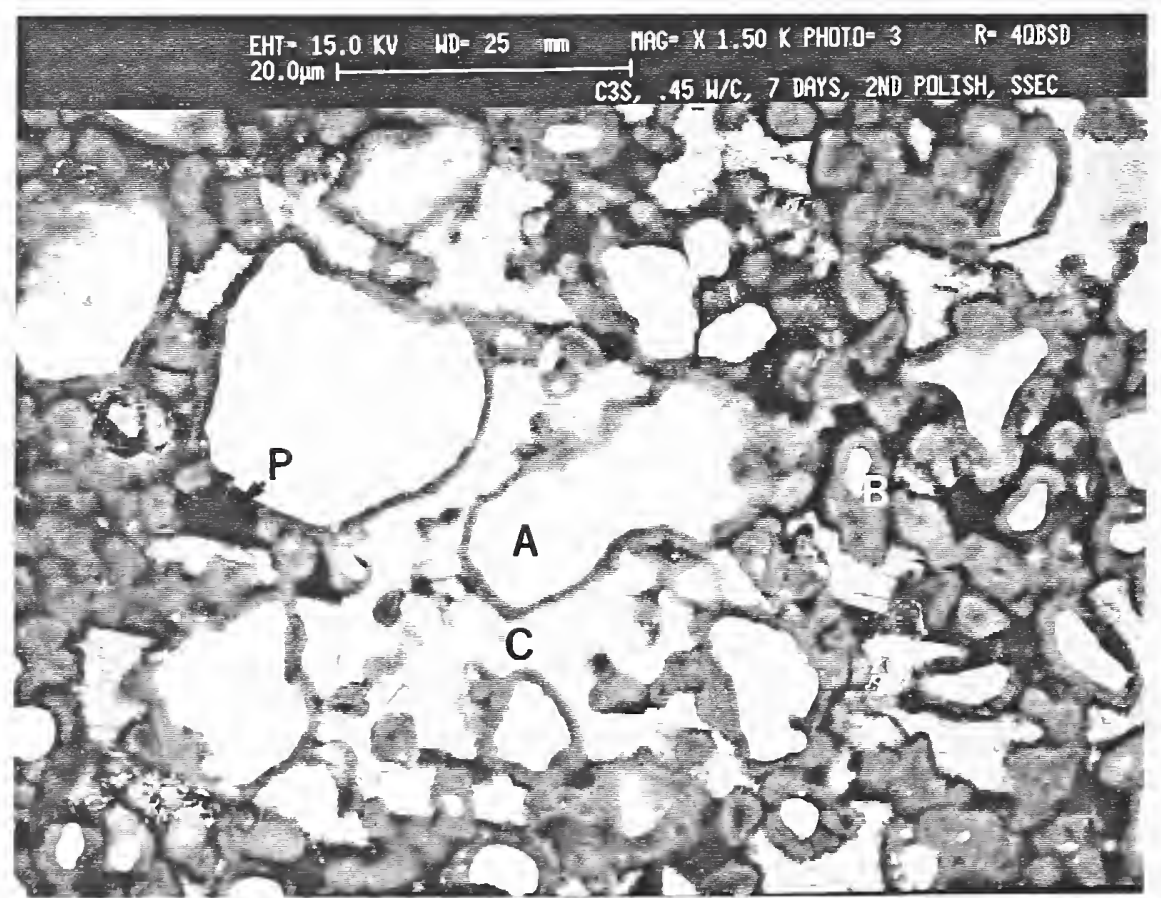

(b)

Figure 3. SEM micrographs of hardened $C_{3} S$ paste sections 1 (a) and 2 (b). (A) unhydrated $\mathrm{C}_{3} \mathrm{~S}$, (B) $\mathrm{C}-\mathrm{S}-\mathrm{H}$, (C) calcium hydroxide, and (P) pore. 


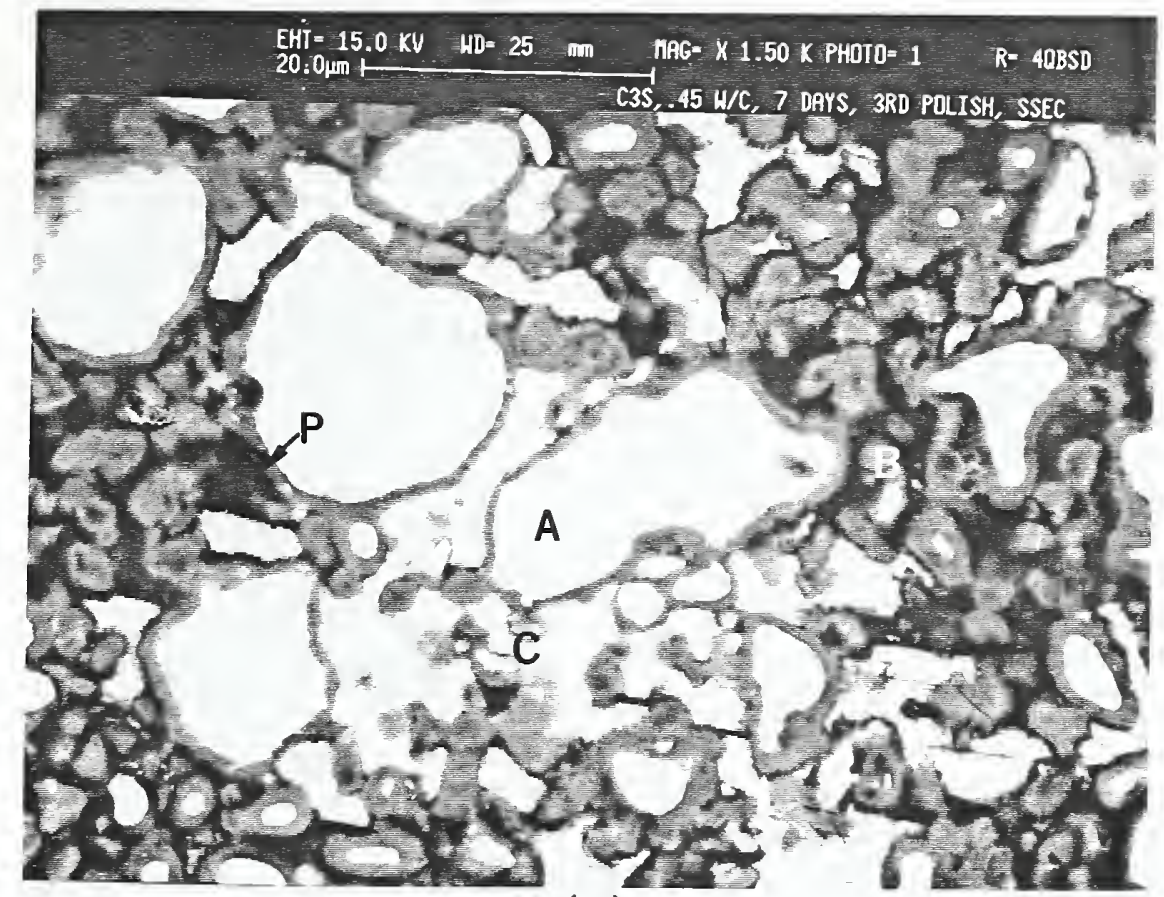

(a)

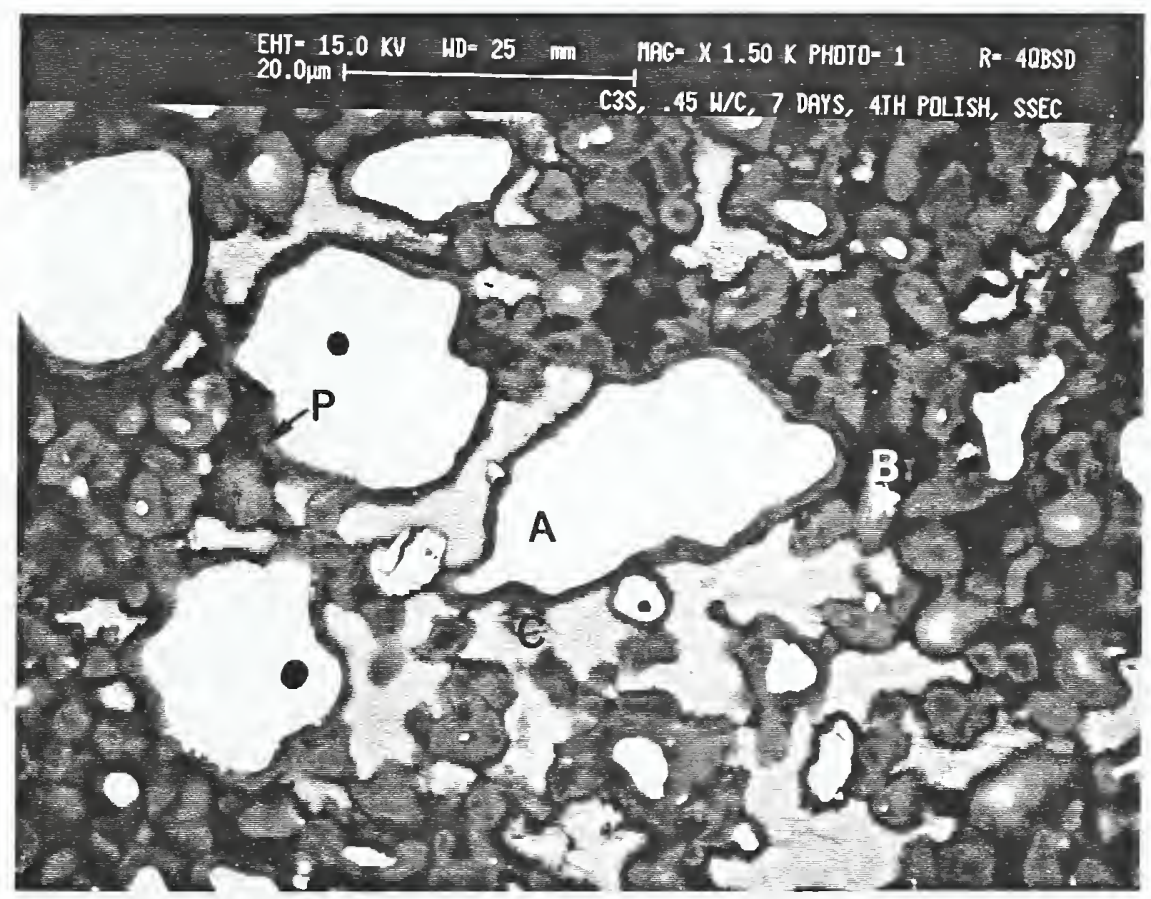

(b)

Figure 4. SEM micrographs of polished sections of $C_{3}$ S paste 3 (a) and 4 (b). 


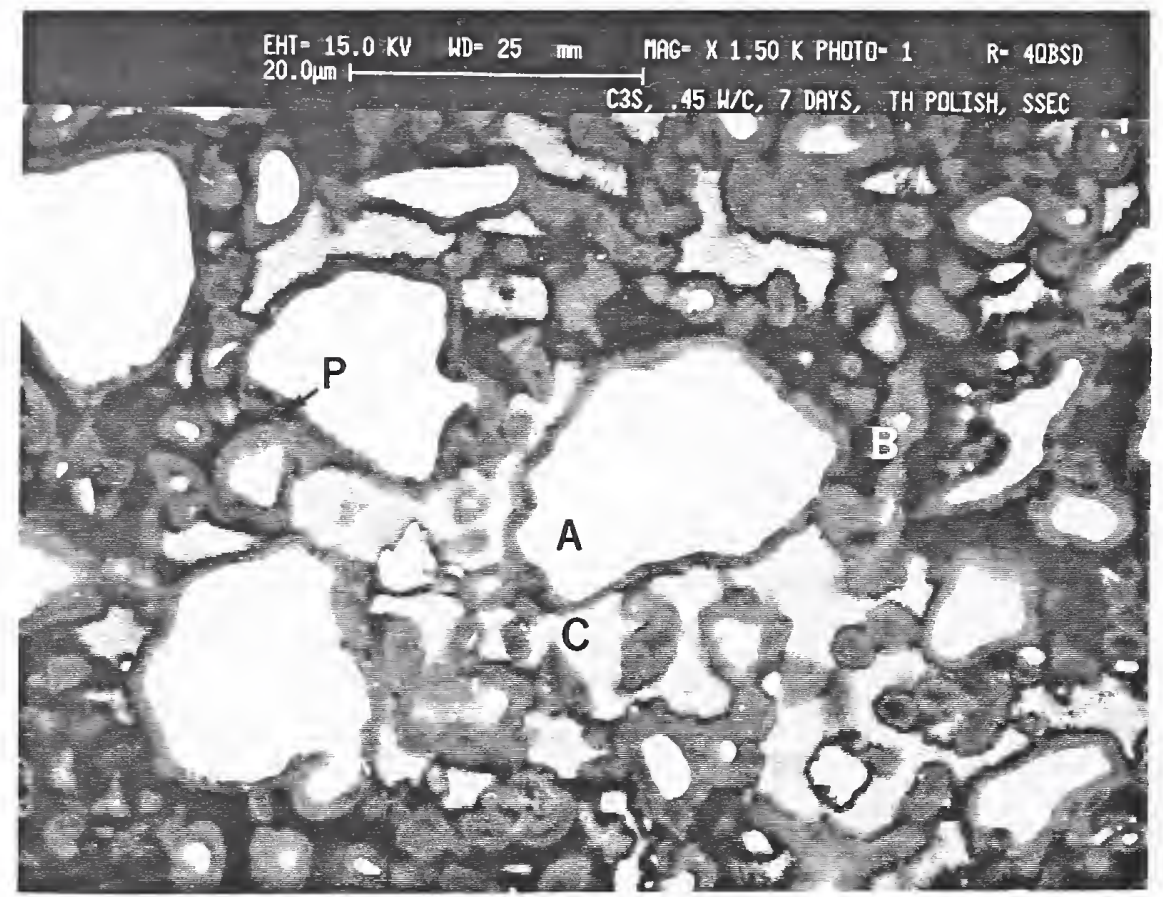

(a)

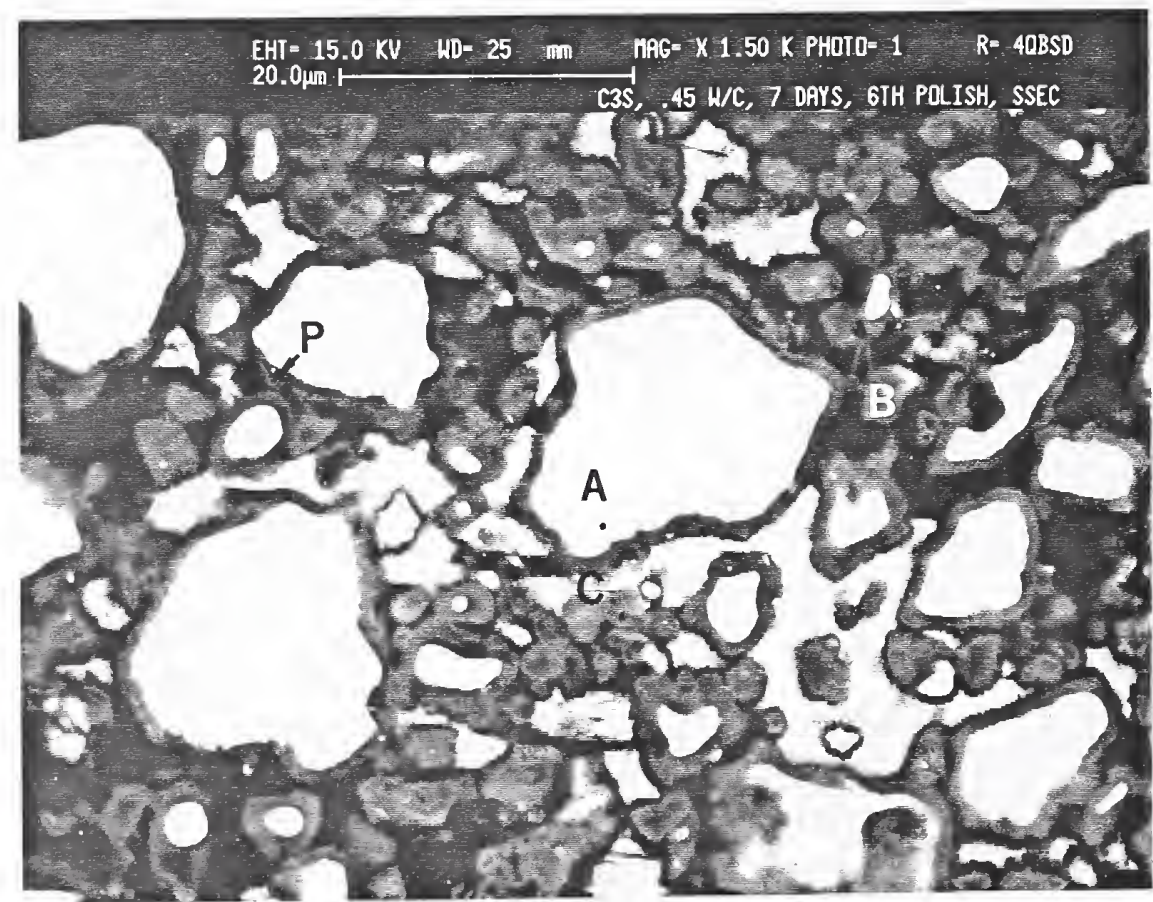

(b)

Figure 5. SEM Micrographs of polished sections of hardened $\mathrm{C}_{3} \mathrm{~S}$ paste 5 (a) and 6 (b). 

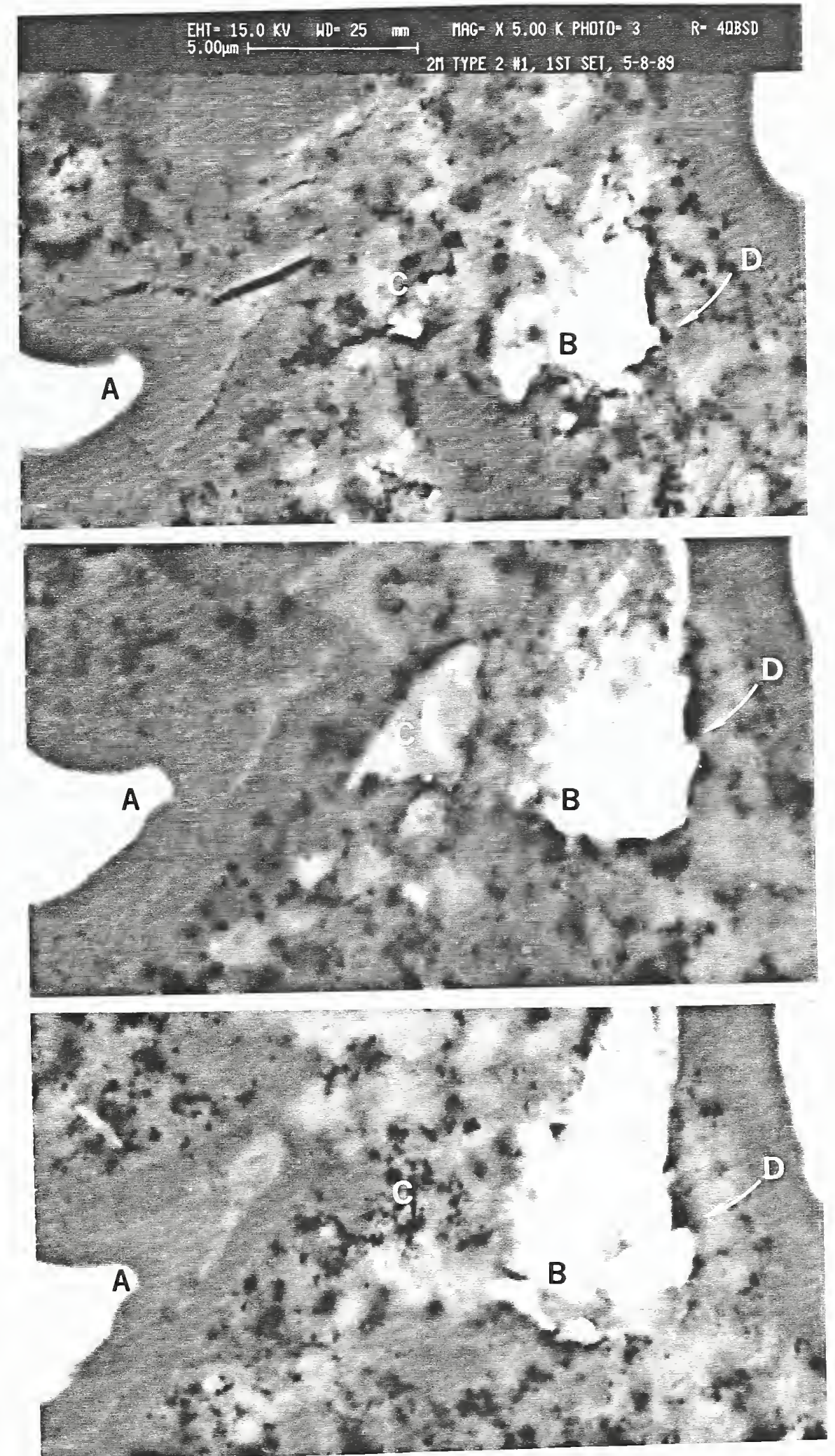

Figure 6. Serial polished sections of hardened portland cement paste. Partially hydrated cement grains, (A), (B), (C), and pore system (D). 
Computer-assisted image analysis alignment techniques exist where adjacent images are compared and shifted until the area of the sectioned feature in the images is minimized [4].

Locating individual unhydrated grains in adjacent images, observing the changes is fairly simple. Some of the smaller C-S$\mathrm{H}$ grains exhibit unhydrated cores as they are sectioned. The capitol letter $\mathrm{P}$ indicates a pore in the cement paste whose changing shape can be observed as layers of cement paste are removed. Initially the pore is seen as an elongated void; in later sections it becomes rounded and connects with other voids. In section 4, a C-S-H grain divides the void into four smaller voids which appear to be isolated. The next section (no. 5) reveals the unhydrated core of the C-S-H grain, the voids are crescent-shaped, some are connected to other voids. In the last image (no. 6), the crescent-shaped voids change to rectangular and triangular voids. Changes in other areas of the cement paste microstructure can be traced as sections are removed.

Figure 6 illustrates the differences in the hardened portland cement paste microstructure shown by sectioning. About one micrometer of cement paste was removed for each section. Because of the finer microstructure, the boundaries between pores, calcium hydroxide and $\mathrm{C}-\mathrm{S}-\mathrm{H}$ can be difficult to establish. Differences in the partially hydrated grains (A), (B), and (C) are apparent at the different depths. While the pores (D) are distinct, following the pore system is not easy because of their fine size. Following any feature in adjacent sections will require a section thickness thinner than the feature of interest and a magnification high enough to clearly image the features. 


\section{CONCLUSIONS}

Serial sections of hardened paste of portland cement and $C_{3} S$ have been made by polishing the specimens. Polishing is a simple means to section the hardened paste as long as water in the polishing lubricants and cleaning fluids is avoided. Section thickness estimation can be made by measuring the change in length of a knoop indentation, and calculating the change in depth for successive sections. Alignment of the sections is done by aligning the Knoop indentation parallel to one of the SEM viewing screen borders for coarse alignment and matching the field of view to a micrograph of the previous section for fine alignment. Beam damaged areas, if deep enough, can be used to align adjacent images. Measurement of microstructural features from multiple sections will aid in the estimation of particle size, shape and distribution. 


\section{ACKNOWLEDGEMENTS}

Critical review and suggestions by Dr. James Clifton and the use of the ion beam milling facilities of Dr. Wen-An Chiou are gratefully acknowledged. This research was sponsored by the National Institute of Standards and Technology. 
7. REFERENCES

1. L. Struble, "Microstructure and fracture at the cement paste-aggregate interface," Materials Research society Symposium Proceedings, Vol. 114, 11-20 (1988).

2. K.L. Scrivener and P.L. Pratt, "Backscattered electron images of polished cement sections in the scanning electron microscope," In: Proceedings of the Sixth International Conference on Cement Microscopy, pp. 145-155. Duncanville: ICMA (1984).

3. L. Struble and P. Stutzman, "Epoxy impregnation of hardened cement for microstructural characterization," Journal of Materials Science Letters, $\underline{8}, 632-634$ (1989).

4. Russ, John C. Computer assisted microscopy, the measurement and analysis of images, Raleigh: North Carolina state University; $1988.356 \mathrm{p}$. 



\begin{tabular}{|c|c|c|}
\hline \multirow[t]{3}{*}{$\begin{array}{l}\text { NIST-114A } \\
\text { (REV. 3-89) }\end{array}$} & \multirow[t]{2}{*}{$\begin{array}{l}\text { U.S. DEPARTMENT OF COMMERCE } \\
\text { NATIONAL INSTITUTE OF STANDARDS AND TECHNOLOGY }\end{array}$} & $\begin{array}{l}\text { 1. PUBLCATION OR REPORT NUMBER } \\
\text { NISTIR } 90-4235\end{array}$ \\
\hline & & 2. PERFORMING ORQANIZATION REPORT NUMBER \\
\hline & \multirow[t]{2}{*}{ BIBLIOGRAPHIC DATA SHEET } & 3. PUBLICATION DATE \\
\hline & & MARCH \\
\hline
\end{tabular}

4. TITLE AND SUBTITLE

Serial Sectioning of Hardened Cement Paste for Scanning Electron Microscopy

5. AUTHOR(S)

Paul Stutzman

6. PERFORMIMG ORGANIZATION (IF JOINT OR OTHER THAN NIST, SEE INSTRUCTIONS)

U.S. DEPARTMENT OF COMMERCE

MATIONAL INSTITUTE OF STANDARDS AND TECHNOLOQY

GAITHERSBURG, MD 20899

7. CONTRACT/GRANT NUMBER

8. TYPE OF REPORT AND PERIOO COVERED

9. SPONSORING ORQANIZATION NAME AND COMPLETE ADDRESS (STREET, CITY, STATE, ZIP)

10. SUPPLEMENTARY NOTES

DOCUMENT DESCRIBES A COMPUTER PROQRAM; SF-185, FIPS SOFTWARE SUMMARY, IS ATTACHED.

11. ABSTRACT (A 200-WORD OR LESS FACTUAL SUMMARY OF MOST SIGMIFICANT INFORMATION. UF DOCUMENT INCLUDES A SIONIFICANT BIBLIOQRAPHY OR UTERATURE SURVEY, MENTION IT HERE.)

Serial sectioning is a technique of making and examining thin sections of material to obtain information on three-dimensional structures from a series of two-dimensional images. Procedures were developed to make serial sections of hardened cement paste by the removal of thin layers by polishing. Backscattered electron imaging of the remaining paste block was used to record the paste microstructure after each section was removed. Procedures developed cover the polishing practice, the removal of thin layers by polishing, the estimation of layer thickness, and the location and alignment of specific regions for imaging.

12. KEY WOADS (6 TO 12 ENTAIES; ALPHABETICAL ORDER; CAPITALZE ONLY PAOPER MAMES; AND SEPARATE KEY WORDS BY SEMICOLONS) backscattered electron imaging; cment paste; Knoop indentation; microstructure; polishing: serial sectioning; scanning electron microscopy

3. AVAILABILTN

$\mathrm{X}$ UNLMTTED

FOR OfFICIAL DISTRIBUTION. DO NOT RELEASE TO MATIONAL TECHMICAL INFORMATION SERVICE (NTIS).

ORDER FROM SUPERINTENDENT OF DOCUMENTS, U.S. GOVERMMENT PRINTING OFFICE, WASHINGTON, DC 20402.

14. NUMBER OF PRINTED PAGES

23

ORDER FROM NATIONAL TECHMICAL INF ORMATION SERVICE (NTIS), SPRIMGFIELD, VA 22161.

\begin{tabular}{|l|} 
14. NUMBER OF PRINTED PAQES \\
23 \\
\hline 15. PRICE \\
$\mathrm{AO} 2$
\end{tabular}



